\title{
Sequential Explanatory Analysis on the Relationship between, Organizational Culture,Transformational Leadership and Personality to Performance
}

\author{
Euis Dedeh Suartilah, Billy Tunas, Widodo Sunaryo \\ Post Graduate Program, Universitas Pakuan Bogor, Indonesia
}

\begin{abstract}
The aim of this study is to examine the influence of Organizational Culture, Transformational Leadership and Personality to Performance of Teachers at Public Junior High Vocational Schools either when tested individually or simultaneously. Organizational Culture, Transformational Leadership and Personality serve as independent variables while the dependent variable is Performance. The research was conducted on proportional randomly selected 205 teachers out of 422 from thirty-one Public Junior High Vocational Schools in Cianjur Regency, West Java Province, Indonesia. Using mix method, the sequential explanatory design is applied where quantitative come first. The study both quantitatively and qualitatively reveals that there is a positive significant relationship among variables under the following distribution of coefficient of correlation: Organizational Culture to Performance $=0.556$, Transformational Leadership to Performance $=0.584$ and Personality to Performance $=0.448$, and when tested together it produces coefficient of correlation $=0.631$ and coefficient of determination $=0.3981$ indicating the contribution of variables including in the model only $39.81 \%$ to performance.
\end{abstract}

Keywords: Organizational Culture, Transformational Leadership, Personality, Performance

\section{INTRODUCTION}

Education is a very strategic vehicle in improving the quality of human resources which is the determinant factor of development. The dignity of a nation is determined by the quality of its education. In the context of the Indonesian nation, improving the quality of education is a target of development in the field of national education and an integral part of efforts to improve the quality of Indonesian human power as a whole. Chapter I Article 1 of Law No. 20 on National Education System states that "education is a conscious and planned effort to create an atmosphere of learning and learning process so that learners actively develop their potential to have spiritual, noble character, as well as the skills required of for self, society, and country ". Without any intention to minimize the contribution of other components, the educator or teacher component is one of an essential factors in determining the quality of learners.

Teachers are at the center of every educational reform effort directed at quality changes. Any educational endeavor such as curriculum replacement, development of teaching methods, the provision of facilities and infrastructure will only be meaningful if it involves the teacher. In addition, teachers are positioned as the front guard in the implementation of teaching and learning process because teachers hold a very strategic position in an effort to create competent and quality graduates to meet the needs of professional human resources. Therefore, the quality and quantity of teachers need to be improved and developed in accordance with current and future needs.

The facts that exist in the field there are still some weaknesses associated with the performance of teachers. A preliminary survey conducted on 41 civil servant teachers at Public Junior High Vocational Schools scattered in 10 districts in Cianjur regency show that teachers are still not maximal to carry out their professional duties.

When accumulated, the number of teachers who always perform the task fully only reaches an average of 17 teachers or only $42.78 \%$ and 24 other teachers or $57.22 \%$ never implemented. This shows that more than half of teachers do not perform their main functions and duties as teachers properly. The facts above show that the performance of teachers in Cianjur Regency is still at a very low level. 
The performance of teachers or employees is influenced by many factors including organizational culture, behavior or leadership style, teacher's own personality, job satisfaction, organizational commitment, motivation, compensation, work environment and others. In this study, the determinant factors suspected to be related to teacher performance are limited to organizational culture, transformational leadership, and personality.

Based on the background and restriction issues to be examined in this study, it is formulated main points as follows:

1. Is there a relationship between Organizational Culture and Performance?

2. Is there a relationship between Transformational Leadership and Performance?

3. Is there a relationship between Personality and Performance?

4. Is there any simultaneous relationship among Organizational Culture, Transformational Leadership, and Personality to Performance?

\section{LiteratURE REVIEW}

Gibson et.al. (2006) defines performance as the level of success in carrying out the task and ability to achieve the goals set. According to Gibson, there are 3 factors that affect the performance, namely: (1) individual factors consisting of: ability, skills, family background, work experience, social level and demography of a person; (2) psychological factors consisting of: perception, role, attitude, personality, motivation and job satisfaction; and (3) organizational factors consisting of: organizational structure, job design, leadership, reward system, rewards, facilities and infrastructure, supervision and support from superiors.

Gaynor (2006) suggests that "performance relates to what teachers do in the classroom and how affects student learning". Teacher performance is closely related to what teachers do in the classroom and how it affects students' learning activities. Teacher teaching performance can also be interpreted as a competence that must be owned by teachers in carrying out their duties and responsibilities.

Based on the definition and theories expressed above, it can be synthesized that performance is the performance of a person in performing tasks in accordance with the responsibilities given and in quality and quantity provide benefits to the organization and in accordance with educational goals. The dimensions and indicators used in the performance variables above are: determining the minimum completeness criteria, creating annual and semester programs, and preparing a Lesson Plan. learning implementation dimension consists of indicators (a) conducting learning preliminary activities, (b) carrying out core learning activities, and (c) carrying out the closing learning activities and the dimension of learning assessment consists of indicators (a) conducting learning assessments, (b) analyzing learning outcomes, and (c) implementing follow-up learning outcomes.

According to Schein (2010), organizational culture is the archetype accepted by organizations to act and solve problems, forming employees who are able to adapt to the environment and unify organizational members. For that it must be taught to members including new members as a correct way of assessing, thinking and feeling the problems faced. The culture within organizations has three basic elements: artifacts, espoused values, and underlying assumptions.

Jones and George (2008) mentioned organizational culture formed by elements (1) personal characteristics and professionalism of people within the organization (characteristics of organizational members), (2) organizational ethics, (3) employment relationship, and (4) organizational structure. When members of the organization have a strong commitment to the beliefs, expectations, values, norms, and habits it uses to achieve its goals, it shows a strong organizational culture. Conversely, if the members of the organization do not have a strong commitment, showing the weak organizational culture. Every organization has a culture, but one organizational culture with another organization is not necessarily the same.

Based on theories about the definition, function, and objectives of organizational culture put forward by the experts above, it can be compiled a synthesis: organizational culture is a trust, values, norms of behavior accepted and socialized on an ongoing basis as a form of organizational characteristics in facing challenges / external adaptation and internal integration. The dimensions of organizational culture include the following: (1) dimensional artifacts which include indicators: (a) symbols, symbols, monuments, logos, and (b) ceremonies and customs. (2) The norms and values include indicators: (a) rules, (b) teacher autonomy, and (c) integrity. (3) Dimensions of basic assumptions that include indicators: (a) professional orientation, (b) goal orientation, and (c) achievement orientation. 
According to Robbins \& Judge (2012) leadership is the ability to influence a group toward achieving a vision or set of goals. The source of this influence may be formal, as provided by managerial ratings in an organization. Leadership factors proposed by Robbins and Judge (2012) include: (a) Initiating structure: the extent to which a leader is likely to define and structure his subordinates in the search for goal attainment. (B) Consideration: the extent to which a leader is likely to have job relationships characterized by mutual trust, respect for subordinates' ideas, and regard for their feelings. (C) Employee-oriented leader: a leader who emphasizes interpersonal relations, takes a personal interest in the needs of employees and accepts individual differences among members.

Avolio and Bass (2002), proposed four dimensions on the basis of transformational leadership with the concept of "4-I" consisting of (1) Idealized influence described as behaviors that generate the respect and confidence of the person they lead. (2) Inspirational motivation is reflected in behaviors that always provide challenges for the work performed by employees and provide meaningful work to them. (3) Intellectual stimulation. Leaders encourage subordinates to be more creative, eliminate the reluctance of subordinates to expel their ideas and in solving problems using new approaches using intelligence and rational reasons. (4) Individualized consideration. Leaders treat others as individuals, considering individual needs and aspirations, listening, educating and training subordinates.

Based on the definitions and opinions of experts put forward above the dimensions and indicators of leadership are as follows. 1) Idealized influence consists of indicators (a) cultivating respect, and (b) having vision and sense of mission. (2) Inspirational motivation (indicator) (a) provides work challenges, and (b) gives positive impetus. (3) Intellectual stimulation (indicator (a) encourages creativity, and (b) approaches intelligence and rationale. (4) Individualized consideration with indicators (a) acting as advisors, and (b) trainers.

The branch of personality psychology acquired a generally acceptable personal taxonomy approach that was the "Big Five Personality" dimension introduced by Goldberg in 1981. The big five elements according to Goldberg (2004) consist of: (1) Openness to Experience: the tendency to be imaginative, independent, and interested in variety vs. practical, conforming, and interested in routine. (2) Conscientiousness: the tendency to be organized, careful, and disciplined vs. disorganized, careless, and impulsive. (3) Extraversion: the tendency to be sociable, fun-loving, and affectionate vs. retiring, somber, and reserved. (4) Agreeableness: the tendency to be softhearted, trusting, and helpful vs. ruthless, suspicious, and uncooperative. (5) Neuroticism: the tendency to be calm, secure, and selfsatisfied vs. anxious, insecure, and self-pitying.

Larsen \& Buss (2002) explains that "personality is a set of psychological trait and mechanisms within a well-organized, relative individual that affect the interaction and adaptation of individuals within the environment (including the physical and social environments)." The elements he proposes including (1) Surgency or extraversion, (2) Agreeableness, (3) Conscientiousness, (4) Emotional Stability, and (5) Intellect or Imagination.

Based on the theoretical explanations and definitions above, the synthesis of personality in this study can be arranged as the overall nature of individuals who tend to be stable in reacting and interacting with other individuals and the environment, which can explain the characteristics of mindset, emotions, and behavior. The dimensions and indicators of personality are (1) Openness to experience with indicators (a) having imagination, (b) having a wide range of insights. (2) Conscientiousness the nature of listening to the conscience, with indicators (a) having the nature of the discipline and (b) meticulous and neat. (3) Extraversion with indicators (a) easy to get along, and (b) fun. (4) Agreeableness with the indicator (a) trustworthy, and (b) likes to help. (5) Emotional stability with indicators (a) calm and (c) preserved.

Based on the study of the theory described above, the following hypothesis is formulated:

1. There is a positive relationship between organizational culture and performance.

2. There is a positive relationship between transformational leadership and performance.

3. There is a positive relationship between personality and performance.

4. There is a positive relationship between organizational culture, transformational leadership and personality, simultaneously with performance.

\section{Methodology}

This study applies Sequential Explanatory Design Mixed Method where the quantitative study is ahead of the qualitative study to examine the relationship between variables tested in the study using three independent variables through data obtained from questionnaires. The independent variable is 
organizational culture $\left(\mathrm{X}_{1}\right)$, transformational leadership $\left(\mathrm{X}_{2}\right)$, and personality $\left(\mathrm{X}_{3}\right)$, while the dependent variable is the performance $(\mathrm{Y})$.

The relationship among variables in the study described in Fig.1 below:

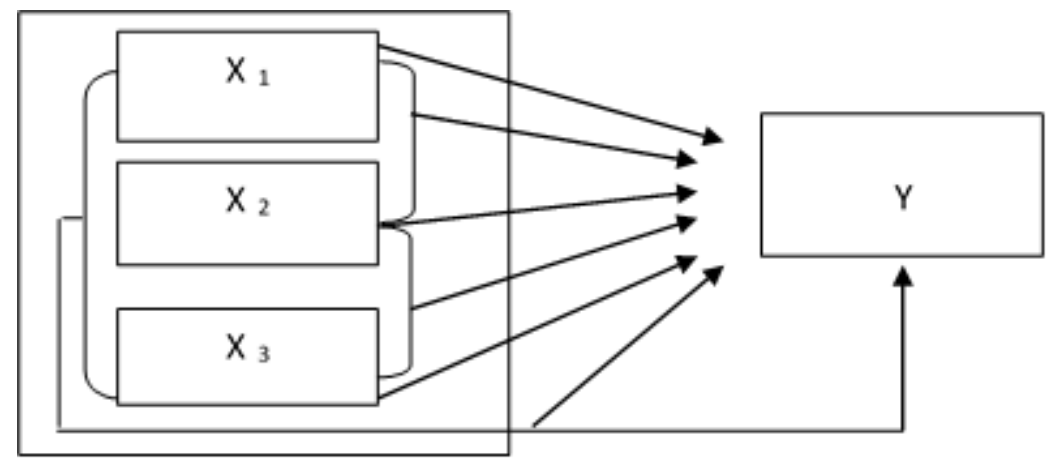

Figure1. Theoretical framework

Where,

$\mathrm{Y}=$ performance

$\mathrm{X}_{1}=$ organizational culture

$\mathrm{X}_{2}=$ transformational leadership

$\mathrm{X}_{3}=$ personality

The sampling technique is to count the number of samples by using the Slovin's formula generating samples obtained as many as 205 respondents out of 422 teachers. Hypothesis testing is conducted by using regression analysis to determine the influence of one or more independent variables on the dependent variable. The normality assumption with Liliefors test are prerequisites to proceeding to further test. Hypothesis testing is performed at a significance level of 0.05 .

Qualitative study for the purpose of confirmation was performed through observation and interview to key informants as well as conducting a focus group discussion with schools' principals and teachers.

\section{RESUlt AND DisCuSSION}

The teachers of listed organizations were asked to participate in the survey by responding their opinions for four different measures in Organizational Culture, Transformational Leadership, Personality and Performance. Data is normal as the value of each variable $=0.0285,0.0608,0.0492$ below the critical value of Liliefors test for $\mathrm{N}=205$ which is 0.0619 .

The result of hypothesis testing shows that functional relationship between organizational culture $\left(\mathrm{X}_{1}\right)$ and teachers' performance $(\mathrm{Y})$ is presented in the form of simple regression equation: $\hat{Y}=97.12+$ $0.39 \mathrm{X}_{1}$ with correlation coefficient value $=0.556$ and coefficient of determination $=0.3091$ with the significant level of 0.05 . This means that $30.91 \%$ variations of teachers' performance can be explained by organizational culture, while the rest is contributed by other variables that have a correlation with teachers' performance improvement. The calculation results obtained t-test $=8.796$ while t-table $(\alpha=$ $0.05)=1.9719$. Since the value of t-test is $>$ than the value of $t$-table, it is concluded that the correlation coefficient between organizational culture and teachers' performance is significant.

Similarly, the result of hypothesis testing shows that functional relationship between transformational leadership $\left(\mathrm{X}_{2}\right)$ and teachers' performance $(\mathrm{Y})$ is presented in the form of simple regression equation: $\hat{Y}=92.01+0.42 X_{2}$ with correlation coefficient value $=0.584$ and coefficient of determination $=$ 0.3411 with the significant level of 0.05 . This means that $34.11 \%$ variations of teachers' performance can be explained by transformational leadership, while the rest is contributed by other variables that have a correlation with teachers' performance improvement. The calculation results obtained t-test $=$ 8.796 while t-table $(\alpha=0.05)=1.9719$. Since the value of t-test is $>$ than the value of t-table, it is concluded that the correlation coefficient between transformational leadership and teachers' performance is significant.

Furthermore, the result of hypothesis testing shows that the functional relationship between personality $\left(\mathrm{X}_{3}\right)$ and teachers' performance $(\mathrm{Y})$ is presented in the form of simple regression equation: 
$\bar{Y}=99.46+0.37 \mathrm{X}_{3}$ with correlation coefficient $=0.488$ and the coefficient of determination $=0.2381$. It means that $23.81 \%$ variation of lecturers' performance can be explained by personality while the rest is contributed by other variables that have correlation with lecturers' performance improvement. The calculation results obtained $t$-test $=7.221$ while $t$-table $(\alpha=0.05)=1.9719$. Since the value of $t$ test is > than the value of $t$-table, it is concluded that the correlation coefficient between personality and teachers' performance is significant.

The result of hypothesis testing shows that the functional relationship between $X_{1}, X_{2}$ and $X_{3}$ with $Y$ are presented in the form of multiple regression equations: $\hat{Y}=32.44+0.34 \mathrm{X}_{1}+0.35 \mathrm{X}_{2}+0.14 \mathrm{X}_{3}$. Since the value of calculated $\mathrm{F}$ at $(\alpha=0.05)=44.401$ is higher than the value of $\mathrm{F}_{\text {tabel }}=2.649$, it is concluded that the relationship between, Organizational Culture $\left(\mathrm{X}_{1}\right)$ and Transformational Leadership $\left(\mathrm{X}_{2}\right)$ and Personality $\left(\mathrm{X}_{3}\right)$ together with Performance is positive and significant. The result of the coefficient determination is 0.3986 meaning that $39.86 \%$ variation of Teachers' Performance variable can be explained by variables of Organizational Culture, Transformational Leadership, and Personality simultaneously while $60.14 \%$ is contributed by other variables that do not include in the model.

In this study, the Principal's Transformational Leadership is the most influencing variable in relation to the Performance of Teachers compared to the Cultural Variables of Organization and Teacher Personality. Transformational Leadership of Principal has a higher coefficient of determination than Organizational Culture variable and Teacher Personality. This means that if the school has a motivational leader, being an inspiration, and providing support to teachers, it will be able to foster a desire and awareness within the teacher to improve performance, at least within the required formal limits.

The results of qualitative research conducted through interviews, observations, and Focus Group Discussion can explain why the transformational leadership variables of principals have a greater relationship with the Performance of Teachers when compared to organizational culture and teacher personality variables. The performance of teachers at Public Junior High Vocational Schools in Cianjur Regency was more influenced by principal leadership behavior. The professional headmaster will accompany and supervise the appearance of teachers and students in school (in class), provide positive and constructive feedback for improvement and development of systems and learning methods, encouraging the effective and creative use of time and learning facilities.

Robbins (2012) defines a transformational leadership style as a leader who has the power to influence subordinates in certain ways. A principal is called applying the rule of transformational leadership style when the principal is able to alter the energy of human resources, instruments, and situations to achieve the goals of school reform. Transformational leadership is the ability of a leader in working with others to transform optimally the organization's resources in achieving meaningful goals in accordance with predetermined achievement targets. The role of the principal's leadership style in implementing renewal efforts in education is very important. Without an aspirational leadership style of leadership, change in the design of any educational reform effort, would not seem to bring optimal results.

\section{CONClusion}

The findings prove that there is a positive and significant relationship between organizational culture, transformational leadership, and personality on teachers' performance among teachers working in public junior high vocational school located in Bekasi, Indonesia. With particular reference to the initial design of the interaction among variables, the results showed that the contribution of organizational culture variable on performance is $30.91 \%$, transformational leadership is $34.11 \%$ and personality is $23.81 \%$ indicating the highest individual contribution to the performance of teachers is principal's transformational leadership. When combined together, the contribution of the three variables of, organizational culture, transformational leadership and personality achieve $39.86 \%$ indicating the contribution of other variables not included in the model to predict the performance of teachers working in public junior high vocational school located in Bekasi Indonesia are $60.14 \%$. Those variables may include working motivation, working environment, disciplines, work satisfaction, commitment and work climate. 


\section{REFERENCES}

[1] Avolio, B.J. ANd Bass, B.M. DeVeloping Potential ACRoss a FUll RANGE of LEADERSHIP CASES ON TRANSACTIONAL AND TRANSFORMATIONAL LEADERSHIP. NEW JERSEY: LAWRENCE ERLBAUM ASSOCIATES. INC..PUBLISHERS. 2002.

[2] Gaynor, A.K. Analyzing Problems in Schools and Schools Systems: A Theoretical Approach. $12^{\mathrm{TH}}$ Edition. Hillsdale, NJ: Lawrence Erlbaum Associates. 2006.

[3] Gibson, James L., John M. Ivancevich \& James H. Donnelly, Jr. Organizations Behavior Structure Processes. 12 ${ }^{\text {th }}$ Edition. (New York: Mcgraw Hill. 2006.

[4] Goldberg, L. R. An Alternative "Description of Personality": The Big-Fife factor structure. Journal of Personality and Social Psychology. 2004.

[5] Jones, Gareth R. \& George, Jennifer M. Contemporary Management (Fifth Edition). USA: McGraw HILL -International. 2008.

[6] Larsen, R. J., Buss, David M. Personality Psychology: Domain of Knowledge about Human Nature. New York: McGraw-Hill. 2002.

[7] Schein, Edgar H. (copyright 1985). Organizational Culture and Leadership. $4^{\text {th }}$ Edition. San Francisco: Jossey-Bass Publishers. 2010.

[8] Robbins, Stephen P. \& Judge, Timothy A. Organizational behavior.- 15th ed. Pearson Education, Inc. New York: Prentice Hall. 2012. 